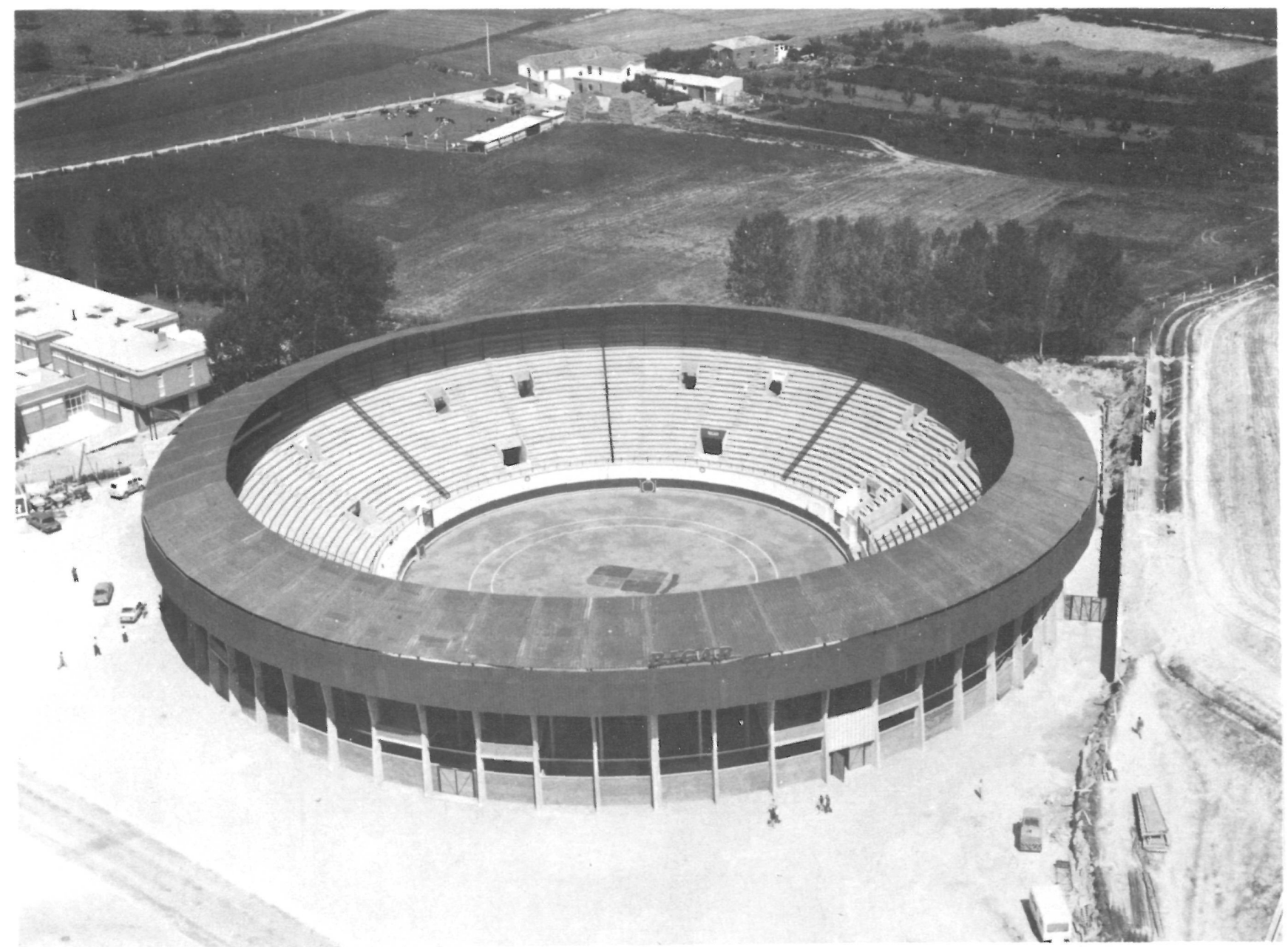

\title{
Plaza de toros de Palencia
}

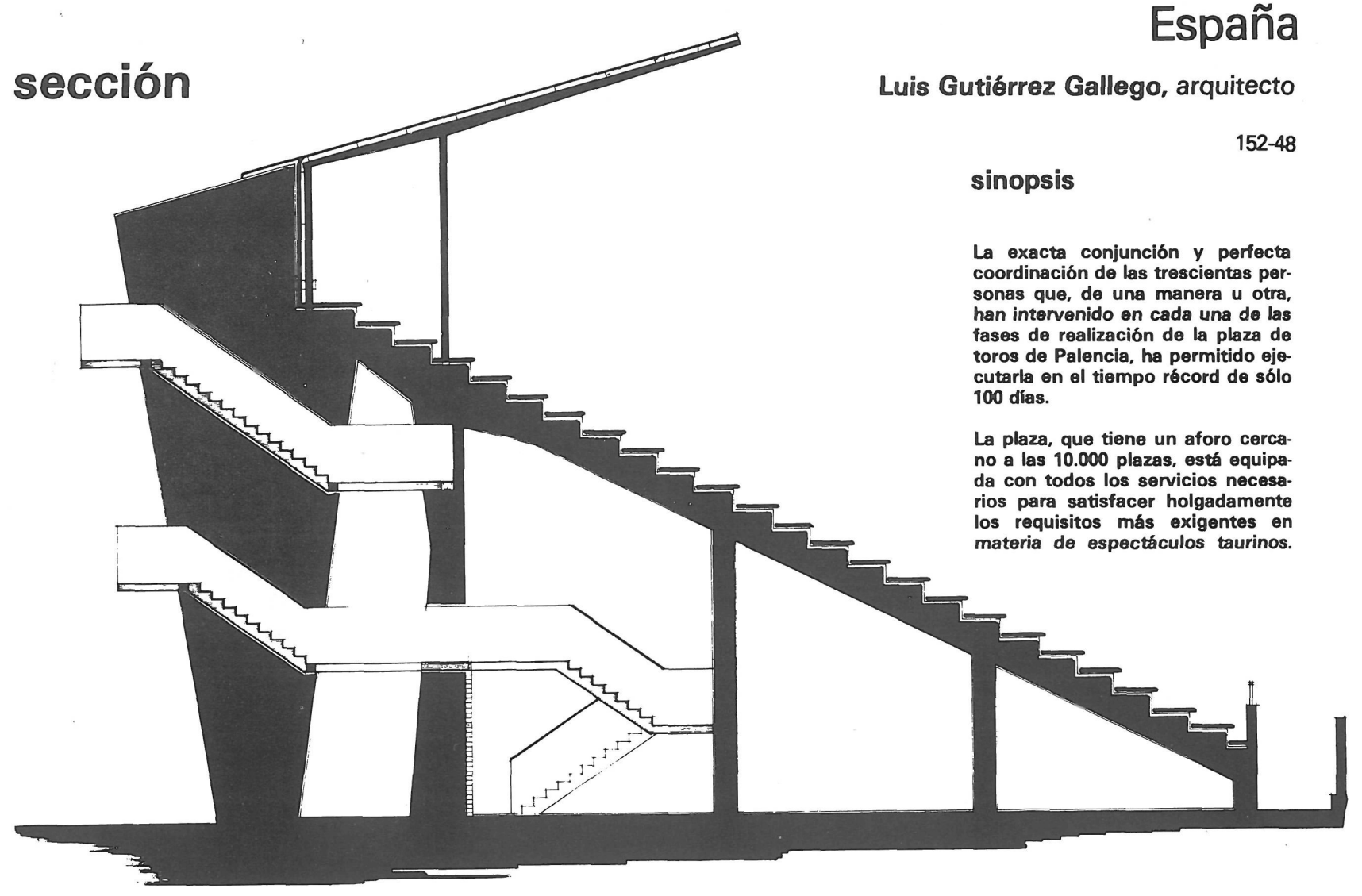




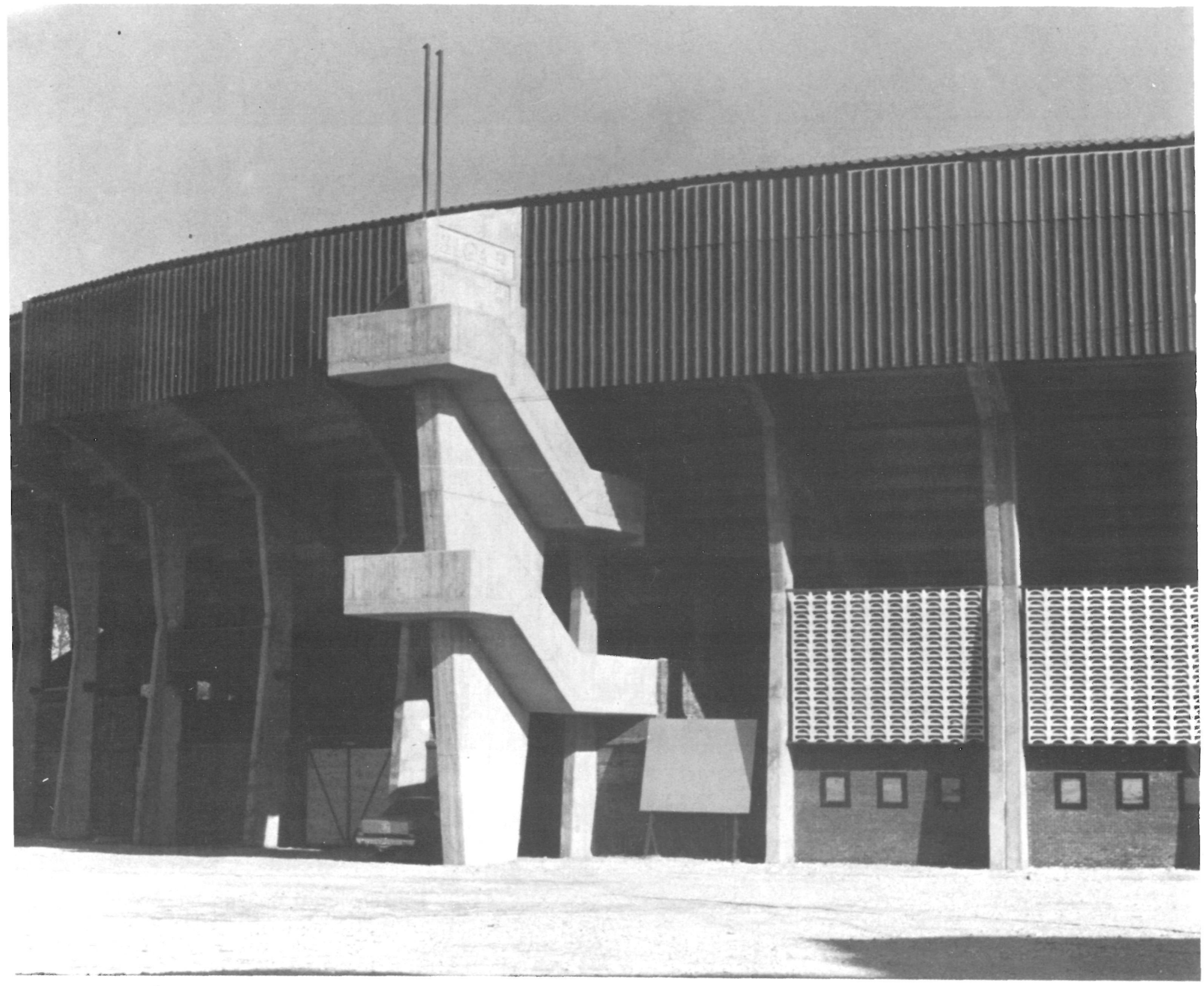

En unos amplios y despejados terrenos de las afueras de Palencia, se ha levantado la nueva plaza de toros de esta capital castellana, sustituyendo a la que, pocos meses atrás, fue demolida para ceder su emplazamiento a un gran complejo residencial.

La plaza, que tiene el récord de haber sido construida en tan sólo cien días, se distribuye en ocho tendidos, con una capacidad aproximada de 1.200 espectadores por tendido. Cada uno de éstos dispone de tres accesos - uno inferior y dos superiores-, y una salida al exterior a través de un portón de $3 \mathrm{~m}$ de anchura.

El diámetro exterior del anillo de la plaza es de $90 \mathrm{~m}$, y de exactamente la mitad el del ruedo, construido a base de una solera de hormigón, sobre la que van los materiales de drenaje necesarios, bajo la capa superior de arena. También es de hormigón el suelo del callejón, de $2 \mathrm{~m}$ de anchura, y que cuenta con los burladeros necesarios de acuerdo con el reglamento taurino. La barrera y el estribo se realizaron de madera, sobre armazón metálico. 

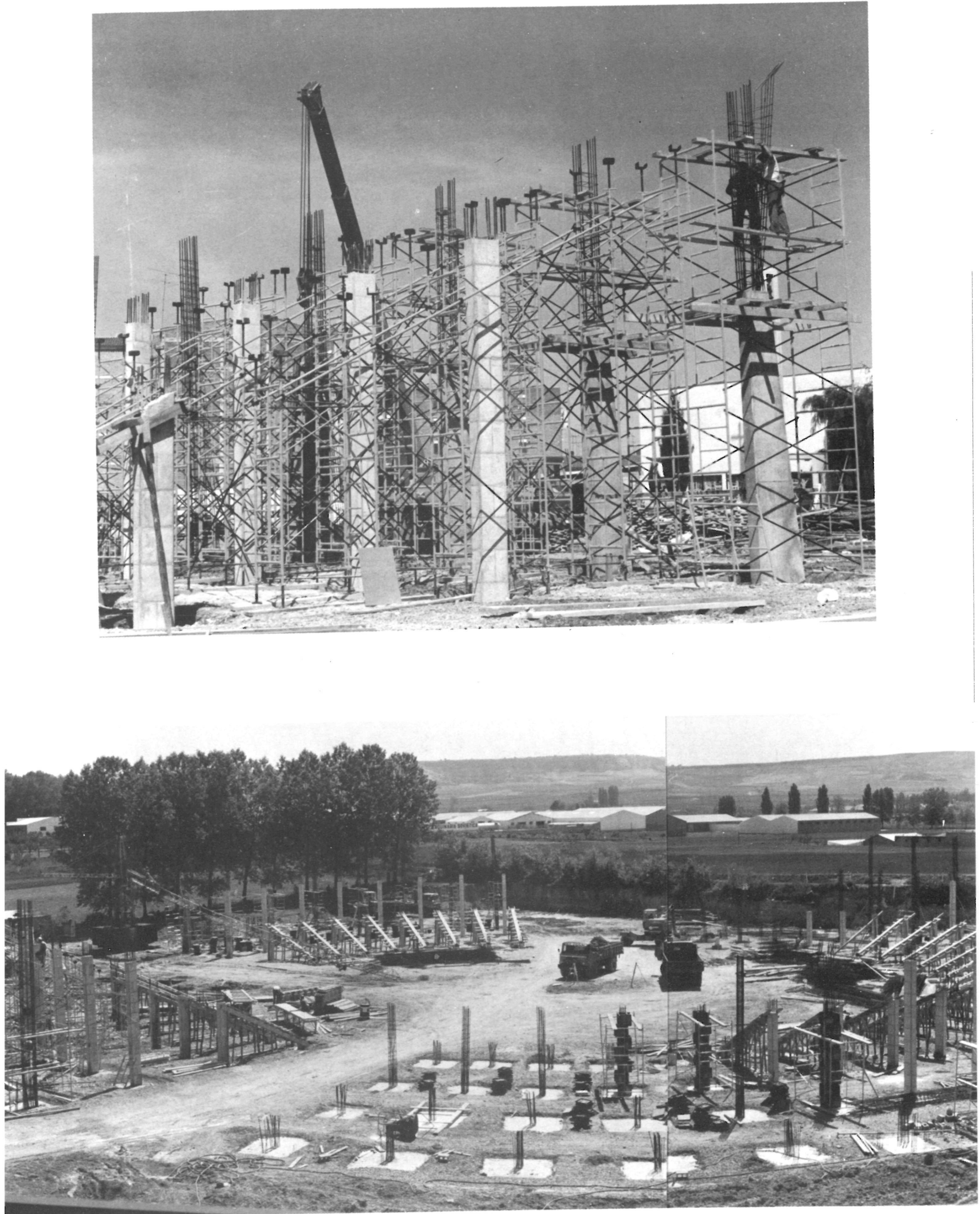

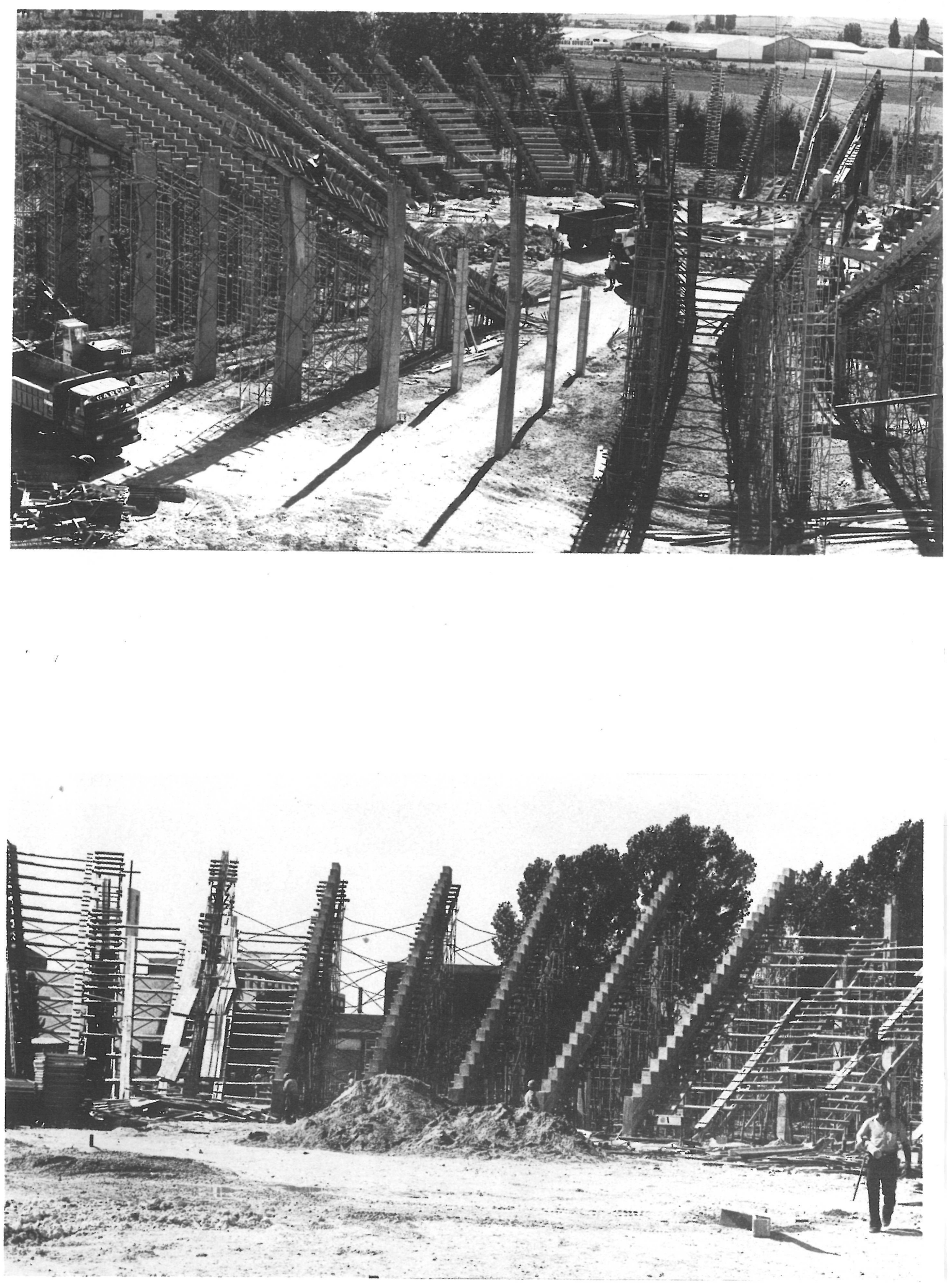


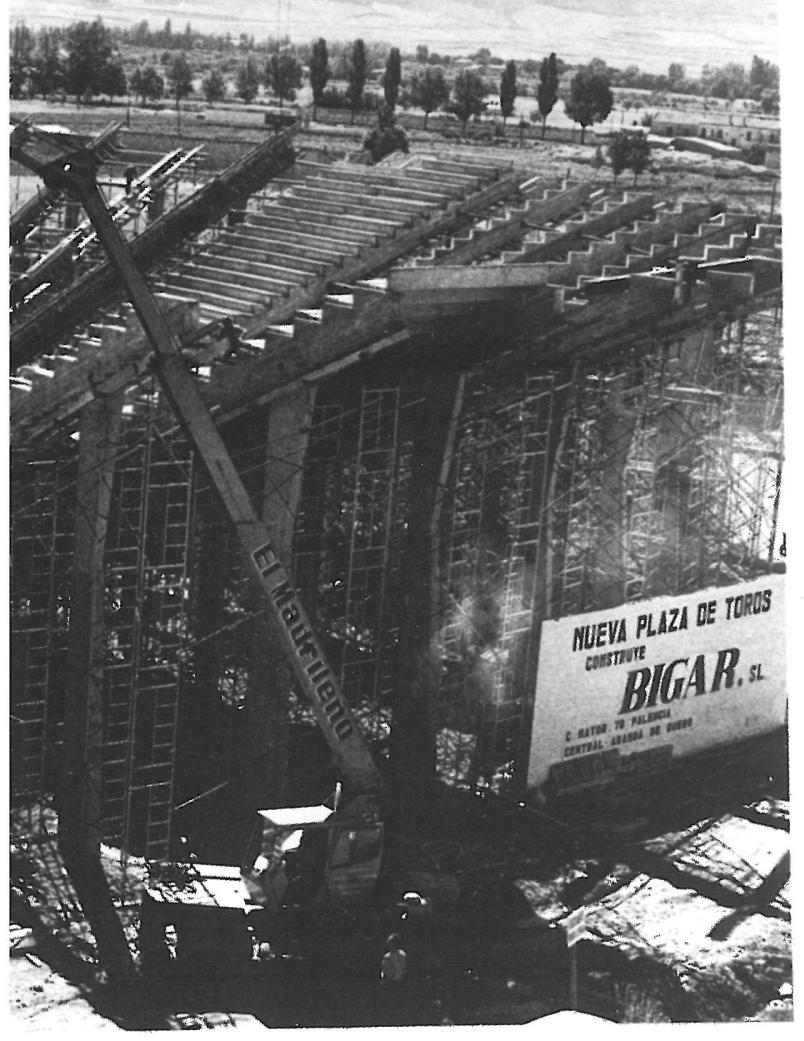

\section{proceso constructivo}
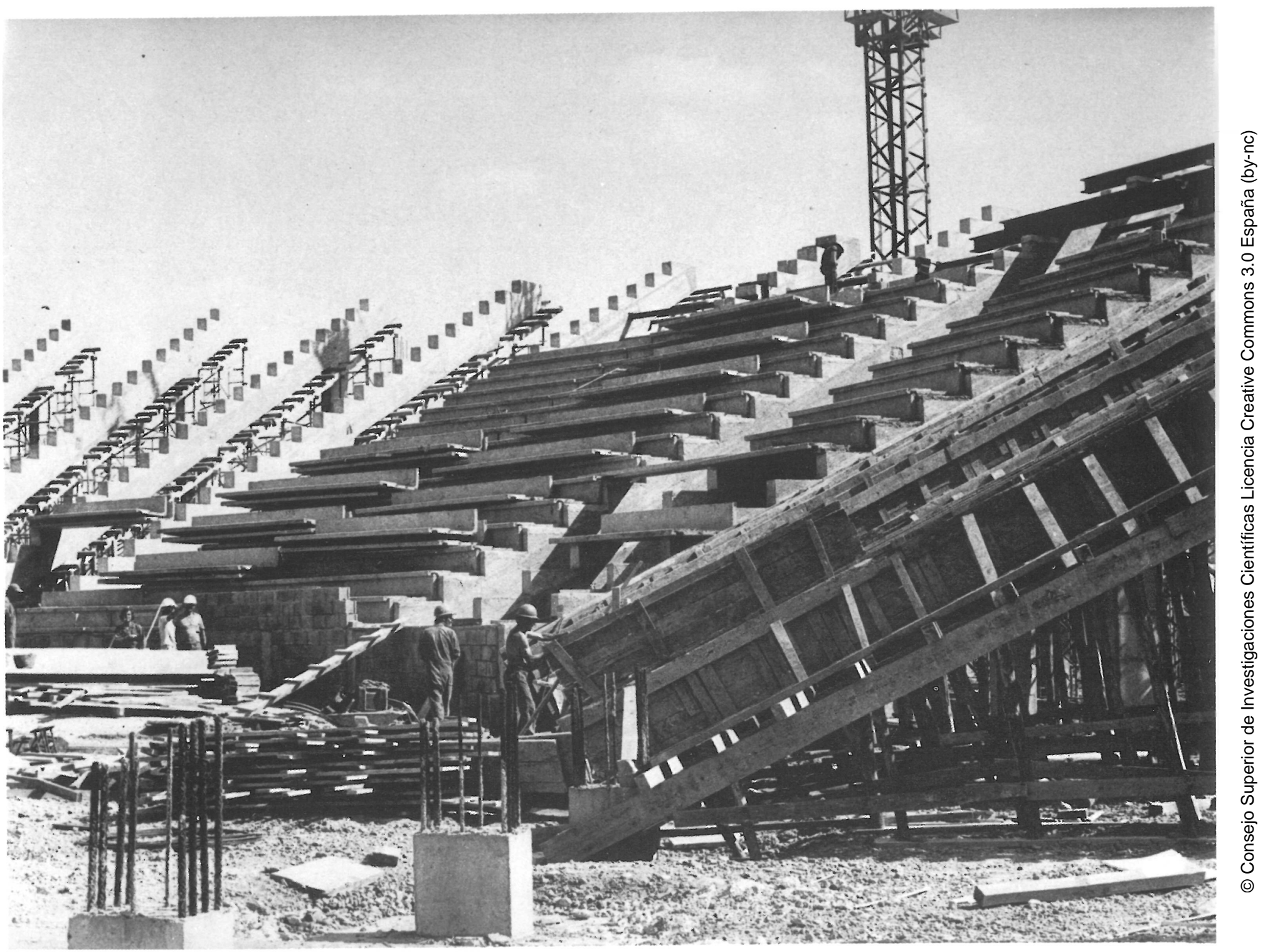

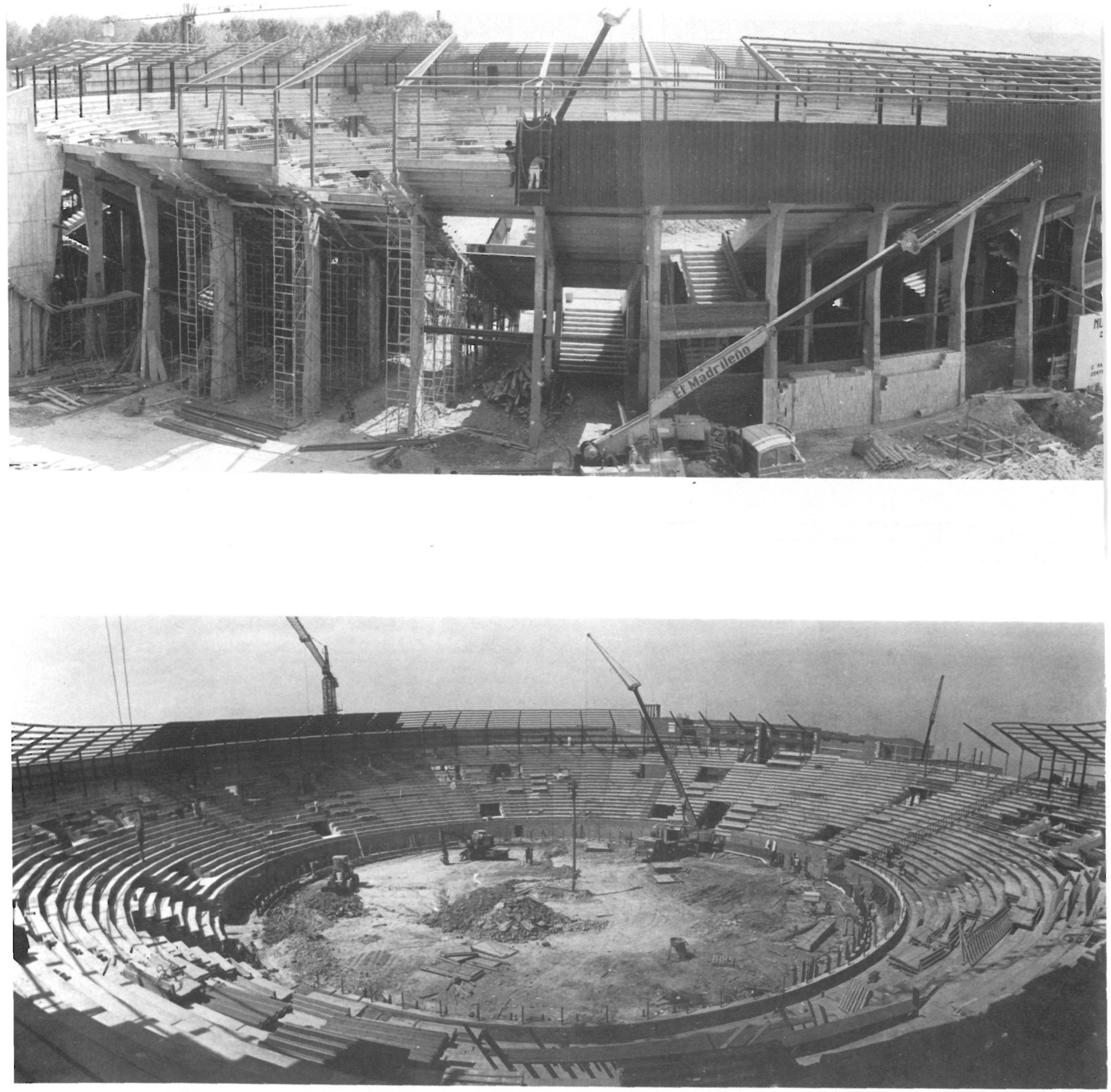

El graderío se llevó a cabo mediante una estructura de hormigón armado formada por 60 pórticos radiales, arriostrados con elementos metálicos, que soportan gradas autoportantes pretensadas. Sobre dichos pórticos se levanta una estructura metálica que sirve de soporte a la cubierta, conformada a base de fibrocemento. El cerramiento exterior se realizó con muro de fábrica de ladrillo y celosía de hormigón.

La plaza dispone de numerosos servicios higiénicos distribuidos en los tendidos. Asimismo cuenta con un equipo completo de enfermería compuesto por sala de reconocimiento, quirófano, sala de recuperación, otra sala de espera, así como los servicios correspondientes. El edificio cuenta también con diversas oficinas y despachos para el veterinario, policía y empresa, asi como con una capilla y un dormitorio para los mayorales. 

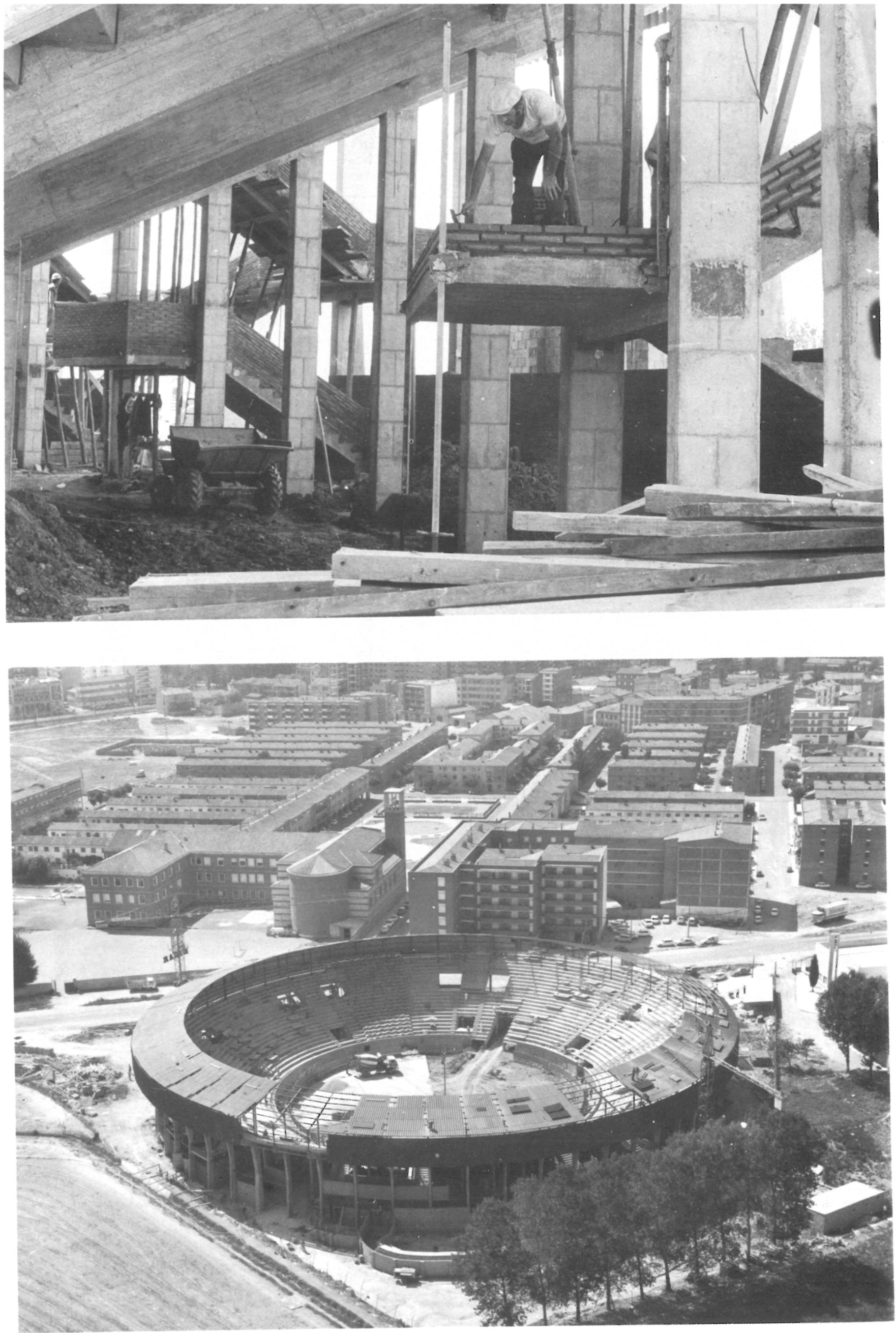
